\title{
Scanning Dysarthria Secondary to Spontaneous Midbrain Hemorrhage
}

\author{
Case Report and Review of Literature
}

\author{
F.J. Alvarez Perez ${ }^{a} \quad$ C. Teijo Nuñez ${ }^{b}$ \\ a Unit of Neurology and ${ }^{b}$ Department of Internal Medicine, Hospital San Juan de Dios, Leon, Spain
}

\section{Dear Sir,}

Acute vascular lesions limited to the midbrain are relatively uncommon and are usually ischemic. Isolated and spontaneous mesencephalic hemorrhages are rare because they are usually a secondary phenomenon resulting either from upward extension of a hemorrhage into the pons or cerebellum, or a downward extension of thalamic or putamen bleeding. The most frequent etiologies of isolated bleedings are arteriovenous malformations and blood dyscrasias, whereas hypertension is an infrequent etiology. Approximately one third of these bleedings remain of unknown cause [1].

Since the microscopic anatomy of the midbrain is extremely complex, the clinical manifestations are broad and include combinations of ataxia and vertigo, different disorders of ocular motility, parkinsonian signs and even hydrocephalus due to aqueduct obstruction. The prognosis as reported in the first descriptions of mesencephalic hemorrhages was poor. However, the increasing use of imaging techniques in recent years has allowed reporting of short series of patients showing more benign bleedings with relatively good clinical outcome.

We report a patient with an isolated midbrain hemorrhage who presented brief clinical manifestations not previously described in the literature. The anatomical correlation is discussed and previous reports of mesencephalic hemorrhages are reviewed.
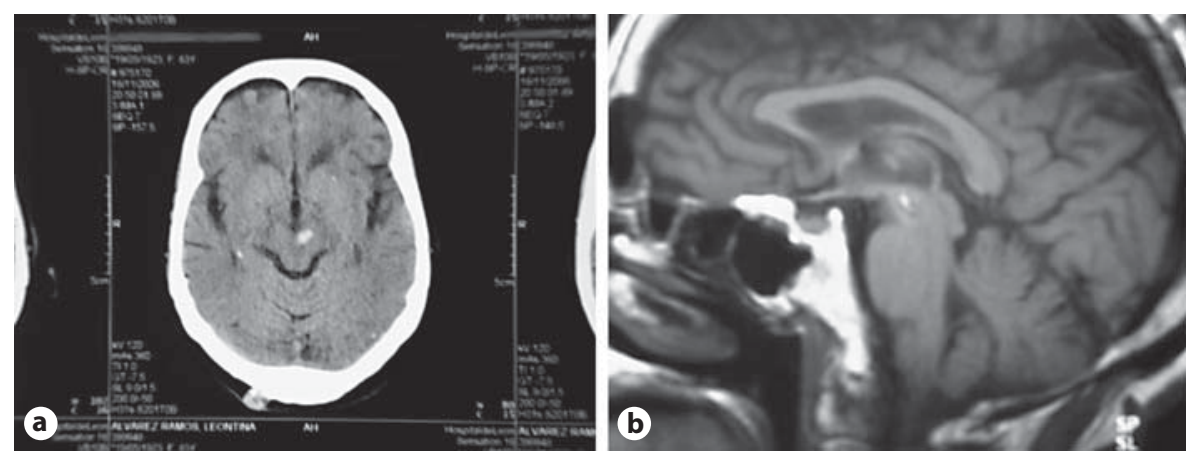

Fig. 1. a Brain CT scan shows a hyperdense lesion in the left cerebral peduncle. b Sagittal MRI shows the same lesion 3 weeks later.

\section{Case Report}

The patient was an 83-year-old woman admitted to our hospital for sudden onset of transient dizziness, limitation on articulation of speech and mild gait instability.

The only relevant antecedent in this patient was type II diabetes mellitus diagnosed 5 years earlier. This vascular risk factor was optimally controlled with habitual doses of 2 oral antidiabetic drugs.

The neurological examination performed on admission showed scanning dysarthria, vertical binocular diplopia in the upward gaze due to a limitation on supraversion of the left eye and mild gait instability with left lateropulsion. No abnormalities of eyelids, diameter of pupils or photomotor responses were observed. Also, the presence of nystagmus, limb ataxia, motor weakness, disorders of sensibility, involuntary movements or impairment of other cranial nerves was excluded.

The noncontrast computed tomography (CT) scan performed on admission showed a 7-mm hyperdense lesion in the mesencephalon, suggestive of acute hemorrhage in the left cerebral peduncle. All laboratory analyses performed, including a coagulation test, anticardiolipin antibodies and lupic anticoagulant, were normal.

The magnetic resonance (MR) imaging study performed 3 weeks later demonstrated the evolution of the bleeding, suggesting a cavernoma as the etiology of the hemor-

\section{KARGER}

Fax +41613061234 E-Mail karger@karger.ch www.karger.com
F.J. Alvarez Perez

San Ignacio de Loyola Avenue, 73

ES-24010 Leon (Spain)

Tel. +34 987232 500, Fax +34987243470

E-Mail franciscoplus@hotmail.com 


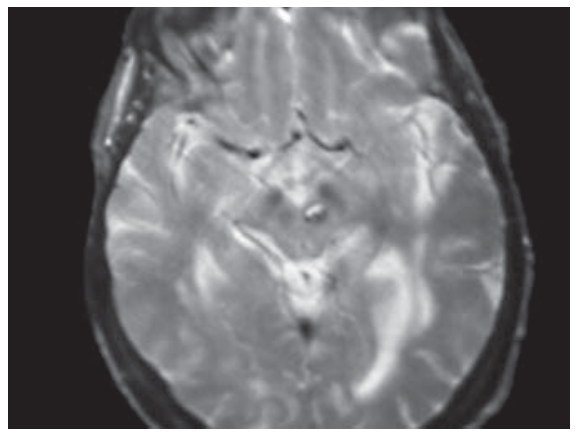

Fig. 2. Axial MRI of the evolution of the hemorrhage at 3 weeks, showing its relation with the red nucleus and the sparing of the corticospinal tract and oculomotor nerve nucleus.

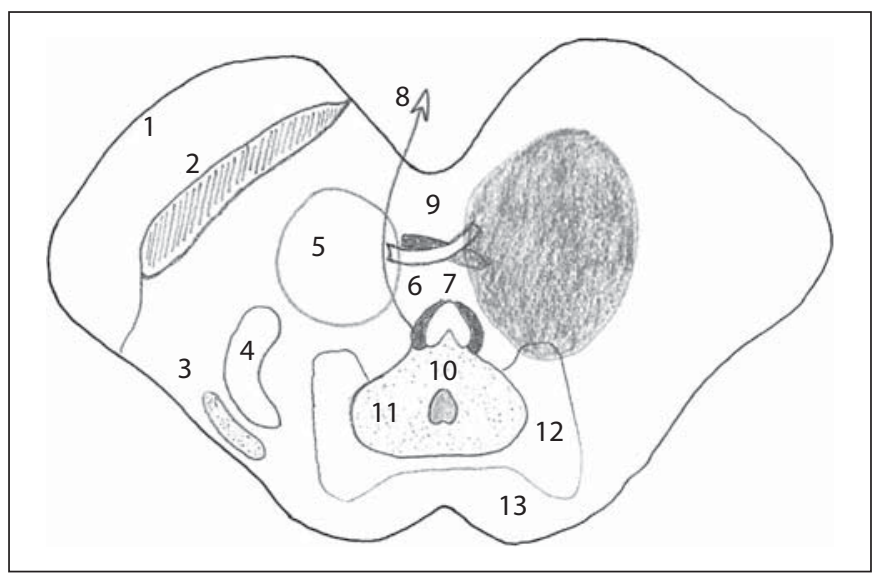

Fig. 3. Schematic representation of mesencephalon. Cross-section at superior colliculus level. Dark circle $=$ Hemorrhagic lesion; $1=$ crus cerebri; 2 = substantia nigra; 3 = brachium inferior colliculus; $4=$ medial lemniscus; $5=$ red nucleus; $6=$ medial longitudinal fasciculus; $7=$ third nerve nucleus; $8=$ third nerve; $9=$ decussation of superior cerebellar peduncles; $10=$ cerebral aqueduct; 11 = central grey; 12 = posterior commissure and nucleus of posterior commissure (projected view from pretectal region); $13=$ superior colliculus.
Table 1. Main clinical manifestations of previously reported patients

\begin{tabular}{|c|c|}
\hline Main clinical manifestation & First author and year \\
\hline Oculomotor nerve palsy & $\begin{array}{l}\text { Shuaib, } 1987 \text { [5] } \\
\text { (2-patient series) } \\
\text { Han, } 1989 \text { [6] } \\
\text { (1 of } 3 \text { patients) } \\
\text { Shintani, } 1994 \text { [7] } \\
\text { Mizushima, } 2002 \text { [8] }\end{array}$ \\
\hline Trochlear nerve palsy & Galetta, 1998 [9] \\
\hline Dorsal midbrain syndrome & $\begin{array}{l}\text { Tomecek, } 1994 \text { [10] } \\
\text { Lee, } 1996 \text { [11] } \\
\text { Bhola, } 2006[12]\end{array}$ \\
\hline \multicolumn{2}{|l|}{ Other oculomotor disorders } \\
\hline $\begin{array}{l}\text { Convergent and downward } \\
\text { deviation }\end{array}$ & Lapresle, 1977 [13] \\
\hline Unilateral dilated pupil & Shuaib, 1989 [14] \\
\hline $\begin{array}{l}\text { Convergence retraction } \\
\text { nystagmus }\end{array}$ & $\begin{array}{l}\text { Han, } 1989[6] \\
\text { (1 of } 3 \text { patients) }\end{array}$ \\
\hline Nuclear ophthalmoplegia & $\begin{array}{l}\text { Han, } 1989[6] \\
\text { (1 of } 3 \text { patients) }\end{array}$ \\
\hline One and a half syndrome & $\begin{array}{l}\text { Ogane, } 1993[15] \\
\text { (1 of } 2 \text { patients) }\end{array}$ \\
\hline $\begin{array}{l}\text { Upward and downward gaze } \\
\text { palsy }\end{array}$ & $\begin{array}{l}\text { Rodriguez-Gomez, } \\
2000 \text { [16] }\end{array}$ \\
\hline \multicolumn{2}{|l|}{ Stroke syndromes of midbrain } \\
\hline Pure sensory stroke & Tuttle, 1984 [17] \\
\hline Nothnagel's syndrome & Shiino, 1986 [18] \\
\hline Weber's syndrome & $\begin{array}{l}\text { Ogane, } 1993[15] \\
\text { (1 of } 2 \text { patients) }\end{array}$ \\
\hline Claude's syndrome & Tsukamoto, 2003 [19] \\
\hline \multicolumn{2}{|l|}{ Movement disorders } \\
\hline Unilateral asterixis & Kida, 1987 [20] \\
\hline Parkinsonian syndrome & Inoue, $1992[21]$ \\
\hline Upper limb dystonia & Esteban Muñoz, 1996 [22] \\
\hline \multicolumn{2}{|c|}{ Consciousness and cognitive manifestations } \\
\hline Spindle coma & Britt, 1980 [23] \\
\hline Peduncular hallucinosis & Hayakawa, 1984 [24] \\
\hline Retrograde amnesia & Mehler, 1988 [25] \\
\hline
\end{tabular}

The list of references is not comprehensive. rhage. Angiographic and echo-gradient sequences were not available. Figures 1 and 2 show the CT and the sagittal and axial $\mathrm{T}_{2}$ weighted MR images, respectively.

The patient had an optimal outcome without specific treatment for the bleeding. Two weeks after the acute event the patient presented a scanning dysarthria and a mild limitation in supraversion of the left eye. She did not show evidence of diplopia or gait instability. Six weeks after admission the only appreciable sequela was the scanning dysarthria.

\section{Discussion}

Reports of patients suffering isolated mesencephalic hemorrhages are relatively infrequent. The longest series are those of Link et al. [2], Weisberg [3] and Fingerote et al. [4], with 7, 6 and 5 patients, respectively. These authors reported neuro-ophthalmologic disorders in the majority of their patients, as well as impairment of consciousness, headache, hemiparesis, hemisensory loss and ataxia. The most frequently reported etiologies were vascular malformations and bleeding diathesis. Hypertension was a relatively uncommon cause, while the etiology remained unknown in one third of the patients. Most patients improved without specific treatment. The majority exhibited no neurological deficits or had only minor neurological sequelae at follow-up.

Other authors have reported series with 1-3 patients. The oculomotor disorders were the most frequent clinical manifestation, especially paresis of the trochlear or oculomotor nerves, and the limita- 
tion of vertical gaze with or without eyelid ptosis. The main clinical manifestations reported in these shorter series are summarized in table 1 .

The reported patient exhibited scanning dysarthria as the main clinical presentation. Oculomotor disorder and gait instability were mild and transitory. In fact, at follow-up, the only relevant sequela was the speech disorder. The axial MR imaging showed that the lesion probably affected the left red nucleus and nearby structures, such as the fascicles of the third cranial nerve, the rostral interstitial nucleus of the medial longitudinal fasciculus (riMLF), the nuclear complex of the posterior commissure (NCPC) and the brachium conjunctivum. Figure 3 represents a cross-section of the mesencephalon at the superior colliculus level including the hemorrhagic lesion, to illustrate the anatomical basis of the clinical picture.

The limitation on supraversion of the left eye, without implication of the pupil and other extrinsic ocular movements, could be related to the interruption of isolated fibers of the oculomotor nerve destined to the superior rectus muscle. It probably coexists with damage of the riMLF or the NCPC. The unilateral lesion of the riMLF has been related to bilateral vertical (upward and downward) gaze palsy [26] and the unilateral lesion of the NCPC has been associated with unilateral upward eye movement and eyelid retraction [27].

Scanning dysarthria is a sign related to cerebellar disease. It is characterized by slow, slurred speech, with increased separation of syllables. Kremer et al. [28] were the first authors to relate scanning dysarthria to a lesion affecting the decussation of the brachium conjunctivum or superior cerebellar peduncle. Considering the localization of the midbrain hemorrhage in our patient, it is probable that the transitory hemiataxia and the more intense and persistent scanning dysarthria were related to the lesion of this bundle. Moreover, damage to this structure may also correlate with the oculomotor disorder. After the decussation of the brachium conjunctivum, a small number of fibers projects into the oculomotor nuclear complex. As most of these fibers end in the cells which innervate the superior rectus, the interruption of this bundle may be related to the described ocular paresis in our patient.
In summary, the complex anatomy of the midbrain justifies the broad spectrum of clinical manifestations related to lesions in this structure. The growing availability of new imaging techniques may enrich the clinical descriptions associated with isolated mesencephalon lesions. To our knowledge, this is the first patient to be reported with a spontaneous and isolated mesencephalic hemorrhage, with scanning dysarthria as the main manifestation. The clinical profile of this rare disorder is thus increased.

\section{References}

1 Kase C, Mohr JP, Caplan LR: Intracerebral hemorrhage; in Mohr JP, Choi D, Grotta J, Wolf P (eds): Stroke. Pathophysiology, Diagnosis, and Management, ed 4. Philadephia, Livingstone, 2004, pp 362-364.

2 Link MJ, Bartleson JD, Forbes G, Meyer FB Spontaneous midbrain hemorrhage: report of seven new cases. Surg Neurol 1993;39:5865.

-3 Weisberg LA: Mesencephalic hemorrhages: clinical and computed tomographic correlations. Neurology 1986;36:713-716.

4 Fingerote RJ, Shuaib A, Brownell AK: Spontaneous midbrain hemorrhage. South Med J 1990;83:280-282.

5 Shuaib A, Murphy W: Mesencephalic hemorrhage and third nerve palsy. J Comput Tomogr 1987;11:385-388.

6 Han SH, Roh JK, Myung HJ: Mesencephalic hemorrhage - a report of 3 cases. J Korean Med Sci 1989;4:1-5.

7 Shintani S, Tsuruoka S, Minato Y, et al: Radiologic-clinical correlation: isolated third nerve palsy caused by midbrain hemorrhage. AJNR Am J Neuroradiol 1994;15:1508-1511.

-8 Mizushima $\mathrm{H}$, Seki T: Midbrain hemorrhage presenting with oculomotor nerve palsy: case report. Surg Neurol 2002;58:417-420.

$\checkmark 9$ Galetta SL, Balcer LJ: Isolated fourth nerve palsy from midbrain hemorrhage: case report. J Neuroophthalmol 1998;18:204-205.

10 Tomecek FJ, Morgan JK: Ophthalmoplegia with bilateral ptosis secondary to midbrain hemorrhage: a case with clinical and radiologic correlation. Surg Neurol 1994;41:131136.

11 Lee AG, Brown DG, Diaz PJ: Dorsal midbrain syndrome due to mesencephalic hemorrhage: case report with serial imaging. J Neuroophthalmol 1996;16:281-285.

12 Bhola R, Olson RJ: Dorsal midbrain syndrome with bilateral superior oblique palsy following brainstem hemorrhage. Arch Ophthalmol 2006;124:1786-1788.
13 Lapresle J, Said G: Forced downward and convergent deviation of the eyes and periodic ocular movements in aneurysmal hemorrhage of the mesencephalic tegmentum (abstract). Rev Neurol (Paris) 1977;133:497.

14 Shuaib A, Israelian G, Lee MA: Mesencephalic hemorrhage and unilateral pupillary deficit. J Clin Neuroophthalmol 1989;9:47-49.

15 Ogane K, Suzuki S, Sobata E, et al: Two cases of well-known syndrome due to midbrainbrain stem hemorrhage - Weber's syndrome and one and a half syndrome (abstract). No To Shinkei 1993;45:163-168.

-16 Rodriguez-Gomez J, Colas J, Aragon A, et al: Upward and downward gaze palsy with a unilateral mesencephalic hemorrhage. Rev Neurol 2000;30:324-326.

17 Tuttle PV, Reinmuth OM: Midbrain hemorrhage producing pure sensory stroke. Arch Neurol 1984;41:794-795.

18 Shiino A, Ichikawa M, Matsuda M, et al: Nothnagel syndrome with midbrain hemorrhage (abstract). Nippon Geka Hokan 1986; 55:789.

19 Tsukamoto T, Miyazawa Y, Taguchi K: Claude's syndrome caused by midbrain hemorrhage (abstract). No To Shinkei 2003;55: 80.

20 Kida Y, Naritomi H, Sawada T, et al: Unilateral asterixis caused by midbrain hemorrhage (abstract). Rinsho Shinkeigaku 1987;27:172.

21 Inoue $\mathrm{H}$, Udaka F, Takahashi M, et al: Secondary parkinsonism following midbrain hemorrhage (abstract). Rinsho Shinkeigaku 1997;37:266.

22 Esteban Munoz J, Tolosa E, Saiz A, et al: Upper-limb dystonia secondary to a midbrain hemorrhage. Mov Disord 1996;11:96-99.

23 Britt CW Jr, Raso E, Gerson LP: Spindle coma, secondary to primary traumatic midbrain hemorrhage (abstract). Electroencephalogr Clin Neurophysiol 1980;49:406.

24 Hayakawa I, Okajima S, Sato K, et al: Hallucinose pedonculaire in a patient with localized midbrain hemorrhage caused by arterio-venous malformation. Rinsho Shinkeigaku 1984;24:472-475.

25 Mehler MF, Ragone PS: Primary spontaneous mesencephalic hemorrhage. Can J Neurol Sci 1988; 15:435-438.

26 Bogousslavsky J, Miklossy J, Regli F, Janzer R: Vertical gaze palsy and selective unilateral infarction of the rostral interstitial nucleus of the medial longitudinal fasciculus (riMLF). J Neurol Neurosurg Psychiatry 1990;53:67-71

27 Schmidtke K, Buttner-Ennever JA: Nervous control of eyelid function: a review of clinical, experimental and pathological data. Brain 1992;115:227-247.

28 Kremer M, Russell WR, Smyth GE: A midbrain syndrome following head injury (abstract). J Neurol Neurosurg Psychiatry 1947; 10:49. 